\title{
Self-worth pada Individu dengan Body Dysmorphic Disorder yang Menjalani Bedah Kosmetik
}

\author{
Janice Valencia1, Atika Amalia Dewi ${ }^{2}$ \\ ${ }^{1}$ Fakultas Psikologi/Universitas Surabaya; Tenggilis Mejoyo, Surabaya, (031) 2981000 \\ ${ }^{2}$ Fakultas Kedokteran/Universitas Brawijaya; Jl. Veteran, Lowokwaru, Malang \\ 1valanciajanice11@gmail.com, 2atikaad03@gmail.com
}

Article History:

Received

2021-11-06

Review

2021-12-13

Revised

2021-12-17

Accepted

2021-12-18

Published

2021-12-28

\begin{abstract}
Body dysmorphic disorder (BDD) is a psychiatry disorder related to body image. Individuals with BDD are found to have low self-worth, this is the cause of individuals with BDD to have cosmetic surgery. The purpose of this article is to determine the relationship of self-worth in individuals with BDD in performing cosmetic surgery. In this systematic review, there were 20 articles that met the criteria, there were 12 articles with the variable self-worth with BDD, 4 articles with the variable self-worth, BDD, and cosmetic surgery, and 4 articles with the variable BDD and cosmetic surgery. Based on the results of a systematic review, it was found that individuals with BDD have low self-worth, this low self-worth makes individuals with BDD perform cosmetic surgery.
\end{abstract}

Keywords: cosmetic surgery, self-worth, body dysmorphic disorder

\begin{abstract}
Abstrak. Body dysmorphic disorder (BDD) merupakan gangguan pada psychiatry yang berhubungan dengan gambaran tubuh. Individu dengan BDD didapatkan mempunya self-worth yang rendah, hal ini menjadi penyebab dari individu dengan BDD untuk melakukan bedah kosmetik. Tujuan dari artikel ini untuk mengetahui hubungan dari self-worth pada individu dengan BDD dalam melakukan bedah kosmetik. Pada sistematik review ini didapatkan 20 artikel yang memenuhi kriteria, terdapat 12 artikel yang terdapat variabel selfworth dengan BDD, 4 artikel dengan variabel self-worth, BDD, dan bedahkosmetik, dan 4 artikel dengan variabel BDD dan bedah kosmetik. Berdasarkan hasil sistematika review didapatkan bahwa individu dengan BDD mempunyai self-worth yang rendah, self-worth yang rendah tersebut membuat individu dengan BDD melakukan bedahi kosmetik.
\end{abstract}

Kata kunci: bedahi kosmetik, self-worth, body dysmorphic disorder

\section{Pendahuluan}

Body dysmorphic disorder (BDD) merupakan gangguan pada psikiatri yang berhubungan dengan gambaran tubuh (Glaser \& Kaminer, 2006). Pada tahun 1886 BDD dikenal juga dengan dysmorphophobia, dysmorphophia berhubungan dengan kekhawatiran dan keluhan terhadap kekurangan pada bagian tubuh. Berasal dari kata dysmorphia yang berarti bad body atau unattractive. Individu dengan BDD mempunyai kecenderungan untuk membayangkan dan melebih-lebihkan kelainan fisik yang bersifat 
minor, individu tersebut cenderung untuk menunjukan pemikiran kesempirnaan dan juga maladaptive attractiveness belief. Perilaku tersebut terjadi terus menerus yang memberikan dampak dalam gangguan fungsi sehari-hari (Buhlmann et al., 2008; Lai et al., 2010).

The etiologi dari BDD multifactorial termasuk biologi, faktor sosiokultur dan psikologi Pada teori psikologi, individu dengan BDD dijelaskan dengan "self-discrepancy theories" yang menjelaskan bahwa individu dengan BDD perbedaan terutama pada poin self-ideal dan self-should (Mufaddel et al., 2013; Veale et al., 2003). Beberapa penelitian mendapatkan bahwa individu dengan riwayat keluarga dengan Obsessive Compulsive Disorder (OCD) mempunyai risiko yang lebih tinggi untuk mendapatkan gangguan seperti obsessive compulsive disorder, body dysmorphic disorder, dan hypochondriasis (Bienvenu et al., 2000; Fang \& Hofmann, 2010). Adanya faktor budaya yang dapat memberikan pengaruh dalam manifestasi BDD seperti di Asia, khususnya di Jepang didapatkan bahwa bagian tubuh yang difokuskan adalah kelopak mata, hal ini dikarenakan adanya perbedaan pemikiran terhadap kecantikan. Berbeda dengan budaya barat dimana muscle dysmorphia lebih banyak ditemukan(Singh \& Veale, 2019).

Penampilan fisik selalu menjadi penilaian terhadap perempuan baik di Barat maupun di Asia, dengan latar belakang bahwa perempuan menarik dari penampilan, hal ini membentuk suatu standart tertentu terhadap ketertarikan yang dapat menjadi beban eksternal. Oleh karena itu, individu membentuk self-worth berdasarkan dari harga yang dinilai lingkungan sosial tersebut (Noser \& Zeigler-Hill, 2014). Contingencies self-worth (CSW) didefinisikan sebagai kepercayaan individu terhadap apa yang harus dilakukan untuk mendapatkan sense of self-worth, hal ini dapat mempengaruhi motivasi individu tersebut, perilakunya, kognisi, dan juga afek (Overstreet \& Quinn, 2012). Crocker and Wolfe's (2001) membagi self-worth menjadi 7 domain yang dapat menyembabkan individu meletakan self-esteem yaitu penampilan, penerimaan dari orang lain, dukungan keluarga, Tuhan, kompetensi akademik, dan kebaikan. Contingencies self-worth yang beruhubungan dengan appearances dengan mempertimbangkan peningkatan, keberhasilan atau kegagalan yang berhubungan dengan penampilan diri secara fisik $(\mathrm{J}$ Crocker \& C.T. Wolfe, 2001; Overstreet \& Quinn, 2012). Penampilan sendiri erat hubungannya dengan body dysmorphic disorder dan juga bedah kosmetik.. Beberapa penelitian mendapatkan bahwa individu yang melakukan bedah kosmetik mempunyai harapan yang tinggi terhadap perubahan yang signifikan dan menjadi lebih baik dibandingkan dengan untuk kebutuhan fungsional (Barone et al., 2015). Selain itu 
terdapat beberapa motivasi dalam individu yang melakukan bedah kosmetik terdapat beberapa individu yang melakukan dikarenakan untuk menyampai standart kecantikan sesuai dengan budaya di lingkungannya, terdapat beberapa individu yang melakukan untuk merubah sosial and emosional, dan juga terdapat beberapa individu yang melakukan untuk fungsionalnya (Adams, 2010). Motivasi dari individu melakukan bedah kosmetik tersebut dapat membantu dalam mendiagnosa body dysmorphic disorder (BDD).

World Health Organization International Classification of Disease 11 (ICD-11) menyatakan bahwa individu body dysmorphic disorder (BDD) mengalami preokupasi terus-menerus terhadap salah satu atau lebih kekurangan yang dirasakan atau kekurangan dalam penampilan yang tidak terlalu mencolok atau hanya sedikit terlihat oleh orang lain. Individu mengalami kesadaran diri yang berlebihan, seringkali dengan ide referensi (yaitu, keyakinan bahwa orang memperhatikan, menilai, atau berbicara tentang cacat atau kekurangan yang dirasakan) (Organisasi Kesehatan Dunia, 2018). Sedangkan Kriteria body dysmorphic disorder berdasarkan DSM-5 body dysmorphic disorder dicirikan sebagai preokupasi dengan defek yang dirasakan atau kekhawatiran yang sangat berlebihan dimana terdapat sedikit anomali fisik, dengan gangguan signifikan terkait dan/atau gangguan fungsional (American Psychiatric Association \& American Psychiatric Association, 2013).

Prevalensi dari Body Dysmorphic Disorder didapatkan pada komunitas dewasa pada masyarakat umum sebanyak 1.9\%, sedangkan persentase tersebut meningkat jika dispesifikan di departmen psikiatri dengan 5.8\% pasien rawat jalan dan $7.9 \%$ pasien rawat inap, dan didapatkan angka tersebut semakin meningkat pada department lainnya seperti general cosmetic surgery $13.2 \%$, rhinoplasty surgery $20.1 \%$, and in cosmetic dermatology outpatients 9.2\%. Data tersebut mendukung data dari American Plastic Surgery didapatkan sejumlah 17.5 juta tindakan bedah kosmetik dan minimally invasive treatment dilakukan pada tahun 2017, sedangkan untuk traditionally plastic surgery seperti liposuction, breast augmentation, dan rhinoplasty didapatkan sebanyak 700.000 tindakan operasi yang dilakukan (American Society of Plastic Surgeons, 2018). Didapatkan juga bahwa terjadi peningkatan di seluruh dunia pada bedah kosmetik sebesar $132 \%$ dibandingkan dengan tahun 2016 (Dean et al., 2018).

Bedah kosmetik merupakan prosedur pembedahan dengan tujuan untuk memperbaiki bagian tubuh yang cacat/tidak sempurna, baik kongenital maupun didapat, yang dapat disebabkan oleh penyakit, trauma, ataupun kejadian fisiologis seperti penuaan. Bedah kosmetik juga didasarkan dari permintaan pasien untuk memperbaiki penampilan, 
dapat dibedakan dengan bedah rekonstruktif yang selalu berhubungan dengan kondisi patologis (Barone et al., 2017).

Dari pengumpulan data yang dilakukan oleh International Society of Aesthetic Plastic Surgery, didapatkan bahwa perbandingan antara prosedur pembedahan dan nonpembedahan yang dikerjakan oleh dokter spesialis bedah plastik untuk tujuan kosmetik yang dilakukan di seluruh dunia pada tahun 2019 adalah 1:1.2, dengan prosedur bedah kosmetik terbanyak adalah pembesaran payudara, sedot lemak, dan disusul oleh pembedahan lipatan mata. Pada penelitian ini juga ditemukan bahwa adanya peningkatan signifikan dari tahun 2015 ke tahun 2019 sebanyak 20.6\% untuk prosedur pembesaran payudara, dan peningkatan sebanyak 22.2\% untuk prosedur sedot lemak. Prosedur pembesaran payudara sudah mulai diminati oleh wanita usia muda yang berusia kurang dari 18 tahun, yang mana 32.3\% tujuan pasien adalah murni untuk kepentingan kosmetik, tanpa ditemukannya kondisi patologis. (ISAPS, 2019).

Berdasarkan penjabaran dan penelitian terdahulu bahwa adanya hubungan antara self-worth pada individu dengan BDD yang melakukan bedah kosmetik. Artikel sistematik review ini bertujuan untuk mengetahui hubungan dari self-worth pada individu dengan body dysmorphic disorder yang melakukan bedah kosmetik.

\section{Metode}

Tinjauan literatur sistematis ini dilakukan sesuai dengan PRISMA. Beberapa sumber yang digunakan dalam tinjauan pustaka sistematis ini, termasuk APA (American Psychological Association), Taylor \& Francis, SAGE, Springer, BMJ, dan ScienceDirect. Dalam proses melakukan tinjauan literatur sistematis, beberapa kata kunci digunakan, termasuk "bedah kosmetik", "body dysmorphic disorder", "self-worth" dan "obsessive compulsive disorder". Kata body dysmorphic disorder bertujuan untuk mengetahui pemahaman konsep diri pada pasien body dysmorphic disorder yang melakukan bedah kosmetik.

Penelusuran kepustakaan telah dilakukan sejak November 2020. Tata cara melakukan penelitian kepustakaan adalah (1) Mengidentifikasi artikel yang melibatkan body dysmorphic disorder dan bedah kosmetik atau (2) Seleksi berdasarkan abstrak dengan menyesuaikan kriteria inklusi dan eksklusi. Literatur yang diperoleh kemudian diseleksi berdasarkan kriteria inklusi yaitu (1) telah melalui proses peer-review, (2) diterbitkan selama 2010-2021, (3) ditulis dalam bahasa Inggris, (4) berisi informasi jumlah sampel. (n) dan peserta yang terlibat. Artikel yang tidak memenuhi kriteria ini dikeluarkan. Selain itu, jika beberapa artikel tidak mengandung informasi untuk 
menjawab pertanyaan penelitian setelah tinjauan lengkap, artikel tersebut juga akan dikecualikan.

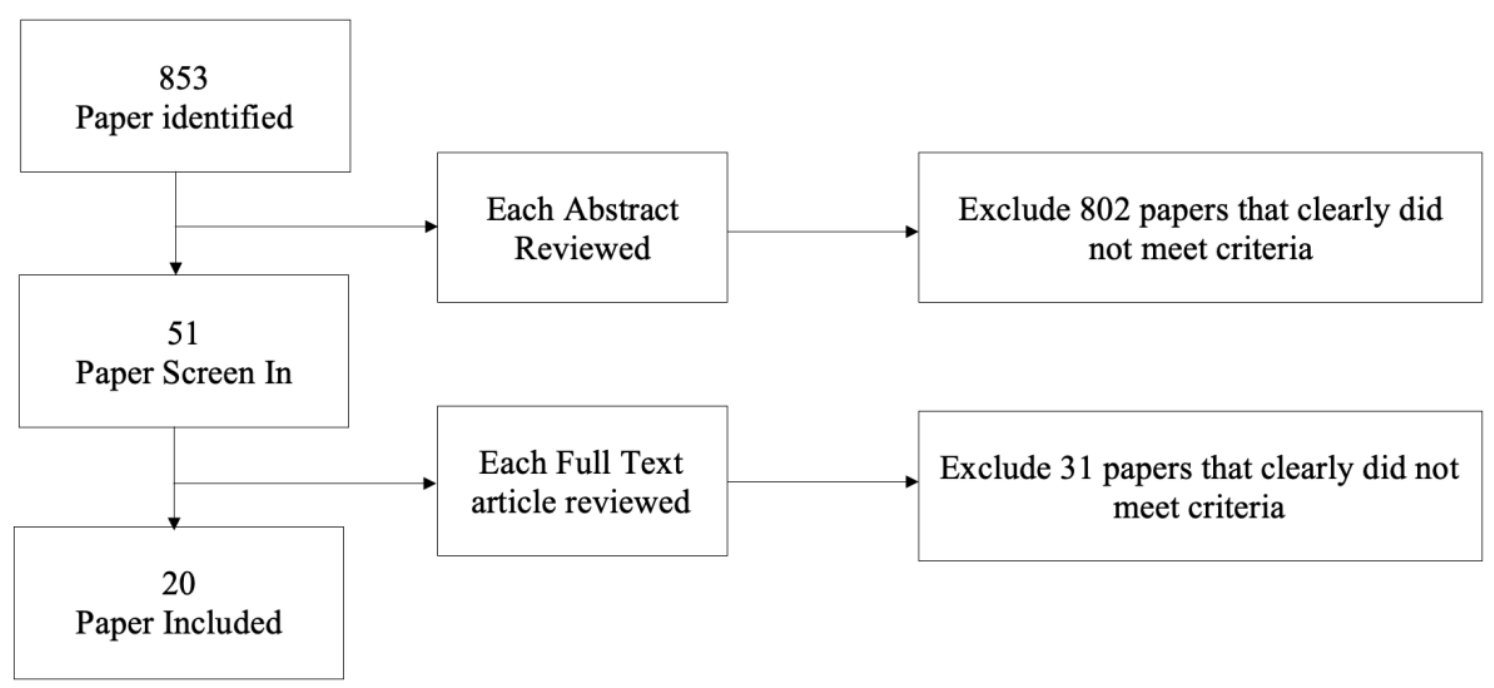

Bagan 1.

Proses pemilihan artikel. Artikel terpilih kemudian dianalisis untuk menjawab pertanyaan penelitian tentang konsep diri pada individu dengan gangguan dismorfik tubuh yang melakukan bedah kosmetik

\section{Hasil}

\section{Body Dysmorphic Disorder dan Self-Worth}

Didapatkan bahwa individu dengan body dysmorphic disorder yang melakukan cosmetic surgery, mempunyai self-worth yang tidak menentu dengan dimensi penampilan, individu melakukan bedah kosmetik untuk merubah penampilan diri dan juga mendapatkan penerimaan dari lingkungan sosial (Overstreet \& Quinn, 2012). Beberapa penelitian mendapatkan bahwa individu dengan BDD melakukan bedah kosmetik untuk mendapatkan penerimaan dari lingkungan sosialnya, dengan adanya penerimaan tersebut hal ini dapat meningkatkan self-worth dan self-esteem (Overstreet \& Quinn, 2012). Terdapat pula pengaruh dari self-knowledge. individu dengan self-knowledge yang tinggi mengalami self-worth yang lebih rendah jika dibandingkan dengan individu yang mempunyai self-knowledge rendah. Hal tersebut dikarenakan individu dengan selfknowledge yang tinggi lebih dapat menangkap ekspresi, emosi, dan perkataan orang lain (Overstreet \& Quinn, 2012). Kesalahan persepsi dari ekspresi, emosi, dan perkataan orang lain membuat individu dengan BDD mempunyai self-worth yang rendah terutama pada self-worth penampilan dirinya (Agustina \& Widhiastuti, 2021; Overstreet \& Quinn, 2012). 


\section{Body Dysmorphic Disorder dan Obsessive Compulsive Disorder}

Didapatkan antar perbedaan individu dengan body dysmorphic disorder dan obsessive compulsive disorder. Pada individu dengan body dysmorphic disorder lebih memperhatikan facial attractive judgement dibandingkan dengan individu dengan obsessive compulsive disorder (Malcolm et al., 2018). Sedangkan untuk penilaian attractiveness diri sendiri, pada individu dengan obsessive compulsive disorder didapatkan angka yang rendah. Individu dengan body dysmorphic disorder merasa dirinya tidak cukup attractive (Ardhani \& Nawangsih, 2020; Malcolm et al., 2018)Terdapat perbedaan antara OCD dengan BDD, pada individu dengan BDD adanya bias dalam visual processing dan juga hyperactivity of detail oriented (Beilharz et al., 2017; Malcolm et al., 2018). Didapatkan juga pada individu dengan BDD lebih preoccupying terhadap facial features dan intensive selection terhadap kekurangan dari penampilan wajah (Green, 2018; Grocholewski et al., 2012; Malcolm et al., 2018).

Pada individu dengan obsessive compulsive disorder dan body dysmorphic disorder, keduanya mengalami missing interpretation, pada BDD berhubungan dengan adanya gangguan dalam visual proses yang dapat menyebabkan gangguan visual attention sehingga berdampak pada kesalahan identifikasi affect. Misinterpretation dari expression pada BDD dapat diinterpretasikan sebagai negative response terhadap penampilan diri, khususnya kekurangan dalam individu BDD (Kollei et al., 2012; Toh et al., 2015).

\section{Body Dysmorphic Disorder dan Bedah Kosmetik}

Semakin bertambahnya pasien bedah kosmetik, terdapat pula peningkatan pasien dengan Body Dysmorphic Disorder yang ditemukan oleh dokter spesialis kulit dan spesialis bedah plastik secara signifikan (Higgins \& Wysong, 2018). Di setiap negara, ditemukan 6 hingga 53 persen pasien bedah kosmetik yang juga didiagnosa sesuai dengan kriteria Body Dysmorphic Disorder (Crerand et al., 2006; Kollei et al., 2012). Body Dysmorphic Disorder sempat dipertimbangkan menjadi kontraindikasi dari prosedur kosmetik baik kasus bedah maupun non-bedah, namun dari studi terbaru pasien dengan kecenderungan BDD akan didampingi oleh tim multidisiplin, tergantung pada tingkat keparahan dan fungsi sosial pasien (Higgins \& Wysong, 2018).

Individu dengan Body Dysmorphic Disorder mempunyai kekhawatiran berlebihan terhadap defek minor yang bahkan orang lain tidak memperhatikannya, merasa dirinya jelek dan terobsesi untuk memperbaiki defek. Area yang biasanya menjadi kekhawatiran 
adalah wajah, hidung, dan kulit (Adams, 2010). Pasien dengan Body Dysmorphic Disorder kerap menjalankan bedah plastik untuk memperbaiki penampilan dan tidak merasa puas sehingga berulang untuk mendapatkan prosedur bedah plastik, seperti rhinoplasty, sedot lemak, rekonstruksi payudara. Studi menemukan bahwa bedah kosmetik tidak selalu memenuhi kepuasan pasien dengan BDD, malah semakin memperburuk kondisi psikologis pasien sehingga bedah plastik dapat dinilai sebagai kontraindikasi pada pasien tersebut (Adams, 2010).

\section{Diskusi}

Permintaan bedah kosmetik dari tahun ke tahun mengalami peningkatan, dapat kita lihat dari adanya peningkatan signifikan pada prosedur bedah kosmetik di seluruh dunia sebesar 132\% dibandingkan dengan tahun 2016 (Dean et al., 2018). Begitu juga dengan pengumpulan data yang dilakukan oleh International Society of Aesthetic Plastic Surgery, didapatkan bahwa adanya peningkatan signifikan dari tahun 2015 ke tahun 2019 sebanyak 20.6\% untuk prosedur pembesaran payudara, dan peningkatan sebanyak 22.2\% untuk prosedur sedot lemak. Prosedur pembesaran payudara sudah mulai diminati oleh wanita usia muda yang berusia kurang dari 18 tahun, yang mana 32.3\% tujuan pasien adalah murni untuk kepentingan kosmetik, tanpa ditemukannya kondisi patologis. (ISAPS, 2019).

Individu dengan BDD yang melakukan bedah kosmetik karena merasa tidak puas dengan tindakan yang dilakukan oleh dokter bedah, sehingga mereka terus meminta perbaikan dari hasil bedah tersebut, tidak jarang pasien dengan BDD langsung merasa tidak puas dengan hasil bedah tersebut. Individu dengan BDD juga mengalami gejala seperti kesulitan tidur, kecewa, marah, dan juga keinginan untuk bunuh diri, sesudah merasa tidak puas dengan hasil bedah (Lai et al., 2010; Ronasih \& Widhiastuti, 2021). Terdapat juga beberapa pasien yang sesudah melakukan bedah kosmetik di salah satu bagian, kemudian berpindah pada bagian lainnya karena merasa tidak puas dengan bagian lainnya, dan siklus tersebut terjadi terus menerus, hal ini membedakan pasien bedah kosmetik yang mengalami BDD dengan yang tanpa BDD (Crerand et al., 2010).

Beberapa penelitian mendapatkan bahwa individu dengan BDD yang melakukan bedah kosmetik mempunyai self-worth yang rendah dan dengan melakukan bedah kosmetik tersebut hal ini meningkatkan self-worth, dengan meningkatnya self-worth individu tersebut merasa bahwa dirinya akan lebih dapat diterima di lingkungan sosialnya (Deng et al., 2019; Jamal \& Sugiarti, 2021). Individu yang melakukan bedah kosmetik pada wajah didapatkan peningkatan pada self-worth, peningkatan tersebut didapatkan selama 
tiga hingga satu tahun, kemudian jika individu tersebut tidak melakukan operasi kembali individu dengan BDD didapatkan penurunan self-worth sehingga individu dengan BDD terus menerus mencari dan melakukan bedah kosmetik (Ayu, 2020; Feijen et al., 2021) Hal tersebut mendukung penelitian yang dilakukan (Noser \& Zeigler-Hill, 2014; Overstreet \& Quinn, 2012; Veale et al., 2003) bahwa individu dengan BDD mempunyai self-worth dan self-esteem yang rendah sehingga untuk meningkatkan self-worth, individu tersebut mencari dan melakukan bedah kosmetik.

\section{Simpulan}

Individu dengan Body Dysmorphic Disorder mempunyai self-worth yang rendah, sehingga individu tersebut melakukan bedah kosmetik untuk meningkatkan self-worth dan self-esteem, sehingga individu lebih percaya diri pada saat berada pada lingkungan sosialnya. Self-worth yang rendah membuat individu tersebut membutuhkan dukungan dan penerimaan dari orang lain atau lingkungannya, sehingga individu BDD dengan selfworth yang rendah berusaha memperbaiki penampilan diri untuk dapat diterima atau mendapat pengakuan terhadap penampilan dirinya.

\section{Saran}

Artikel ini menjelaskan tentang hubungan dari self-worth pada individu dengan BDD yang melakukan operasi kosmetik, perlunya penelitian lebih lanjut yang melibatkan selfesteem, faktor budaya, dan juga kepribadian. Penelitian lebih lanjut diperlukan untuk mengetahui faktor lain yang berpengaruh pada individu dengan BDD yang melakukan operasi kosmetik dan juga memberikan terapi non-farmakologi dan farmakologi yang tepat.

\section{Kepustakaan}

Adams, J. (2010). Motivational Narratives and Assessments of the Body After Cosmetic Surgery. Qualitative Health Research, 20(6), 755-767. https://doi.org/10.1177/1049732310362984

American Psychiatric Association, \& American Psychiatric Association (Eds.). (2013). Diagnostic and statistical manual of mental disorders: DSM-5 (5th ed). American Psychiatric Association.

American Society of Plastic Surgeons. (2018). National clearinghouse of plastic surgery procedural statistics-2017.

Barone, M., Cogliandro, A., La Monaca, G., Tambone, V., \& Persichetti, P. (2015). Cognitive Investigation Study of Patients Admitted for Cosmetic Surgery: Information, Expectations, and Consent for Treatment. Archives of Plastic Surgery, 42(1), 46. https://doi.org/10.5999/aps.2015.42.1.46

Barone, M., Cogliandro, A., \& Persichetti, P. (2017). Ethics and Plastic Surgery/What is Plastic Surgery? Archives of Plastic Surgery, 44(1), 90-92. 
https://doi.org/10.5999/aps.2017.44.1.90

Beilharz, F., Castle, D. J., Grace, S., \& Rossell, S. L. (2017). A systematic review of visual processing and associated treatments in body dysmorphic disorder. Acta Psychiatrica Scandinavica, 136(1), 16-36. https://doi.org/10.1111/acps.12705

Bienvenu, O. J., Samuels, J. F., Riddle, M. A., Hoehn-Saric, R., Liang, K.-Y., Cullen, B. A. M., Grados, M. A., \& Nestadt, G. (2000). The relationship of obsessive-compulsive disorder to possible spectrum disorders: Results from a family study. Biological Psychiatry, 48(4), 287-293. https://doi.org/10.1016/S0006-3223(00)00831-3

Buhlmann, U., Etcoff, N. L., \& Wilhelm, S. (2008). Facial attractiveness ratings and perfectionism in body dysmorphic disorder and obsessive-compulsive disorder. Journal of Anxiety Disorders, 22(3), 540-547. https://doi.org/10.1016/j.janxdis.2007.05.004

Crerand, C. E., Franklin, M. E., \& Sarwer, D. B. (2006). Body Dysmorphic Disorder and Cosmetic Surgery: Plastic and Reconstructive Surgery, 118(7), 167e-180e. https://doi.org/10.1097/01.prs.0000242500.28431.24

Crerand, C. E., Menard, W., \& Phillips, K. A. (2010). Surgical and Minimally Invasive Cosmetic Procedures Among Persons With Body Dysmorphic Disorder. Annals of Plastic Surgery, 65(1), 11-16. https://doi.org/10.1097/SAP.0b013e3181bba08f

Dean, N. R., Foley, K., \& Ward, P. (2018). Defining cosmetic surgery. Australasian Journal of Plastic Surgery, 1(1), 37-45. https://doi.org/10.34239/ajops.v1n1.29

Deng, Y., Chen, Y., \& Liu, X. (2019). Romantic relationship and appearance-based rejection sensitivity: A moderated mediation model of self-rated attractiveness and appearance-contingent self-worth. Personality and Individual Differences, 142, 295300. https://doi.org/10.1016/j.paid.2018.09.010

Fang, A., \& Hofmann, S. G. (2010). Relationship between social anxiety disorder and body dysmorphic disorder. Clinical Psychology Review, 30(8), 1040-1048. https://doi.org/10.1016/j.cpr.2010.08.001

Feijen, M. M. W., van Cruchten, C., \& van der Hulst, R. R. W. J. (2021). The Effect of Cranial Shape on Esthetic Self-Worth in Bald Men. Journal of Craniofacial Surgery, 32(1), 233-237. https://doi.org/10.1097/SCS.0000000000006916

Glaser, D. A., \& Kaminer, M. S. (2006). Body Dysmorphic Disorder and the Liposuction Patient. Dermatologic Surgery, 31(5), 559-561. https://doi.org/10.1111/j.15244725.2005.31161

Green, J. L. (2018). Peer support systems and professional identity of student nurses undertaking a UK learning disability nursing programme. Nurse Education in Practice, 30, 56-61. https://doi.org/10.1016/j.nepr.2017.11.009

Grocholewski, A., Kliem, S., \& Heinrichs, N. (2012). Selective attention to imagined facial ugliness is specific to body dysmorphic disorder. Body Image, 9(2), 261-269. https://doi.org/10.1016/j.bodyim.2012.01.002

Higgins, S., \& Wysong, A. (2018). Cosmetic Surgery and Body Dysmorphic Disorder - An Update. International Journal of Women's Dermatology, 4(1), 43-48. https://doi.org/10.1016/j.ijwd.2017.09.007

ISAPS. (2019). International Survey on Aesthetic/Cosmetic Procedures.

J Crocker \& C.T. Wolfe. (2001). Contingencies of self-worth. Psychological Review, 108(3), 593.

Kollei, I., Brunhoeber, S., Rauh, E., de Zwaan, M., \& Martin, A. (2012). Body image, emotions and thought control strategies in body dysmorphic disorder compared to eating disorders and healthy controls. Journal of Psychosomatic Research, 72(4), 321-327. https://doi.org/10.1016/j.jpsychores.2011.12.002

Lai, C.-S., Lee, S.-S., Yeh, Y.-C., \& Chen, C.-S. (2010). Body Dysmorphic Disorder in Patients With Cosmetic Surgery. The Kaohsiung Journal of Medical Sciences, 26(9), 478-482. 
https://doi.org/10.1016/S1607-551X(10)70075-9

Malcolm, A., Labuschagne, I., Castle, D., Terrett, G., Rendell, P. G., \& Rossell, S. L. (2018). The relationship between body dysmorphic disorder and obsessive-compulsive disorder: A systematic review of direct comparative studies. Australian \& New Zealand Journal of Psychiatry, 52(11), 1030-1049. https://doi.org/10.1177/0004867418799925

Mufaddel, A., Osman, O. T., Almugaddam, F., \& Jafferany, M. (2013). A Review of Body Dysmorphic Disorder and Its Presentation in Different Clinical Settings. The Primary Care Companion For CNS Disorders. https://doi.org/10.4088/PCC.12r01464

Noser, A., \& Zeigler-Hill, V. (2014). Investing in the ideal: Does objectified body consciousness mediate the association between appearance contingent self-worth and appearance self-esteem in women? Body Image, 11(2), 119-125. https://doi.org/10.1016/j.bodyim.2013.11.006

Overstreet, N. M., \& Quinn, D. M. (2012). Contingencies of Self-Worth and Appearance Concerns: Do Domains of Self-Worth Matter? Psychology of Women Quarterly, 36(3), 314-325. https://doi.org/10.1177/0361684311435221

Singh, A., \& Veale, D. (2019). Understanding and treating body dysmorphic disorder. Indian Journal of 131. https://doi.org/10.4103/psychiatry.IndianJPsychiatry_528_18

Toh, W. L., Castle, D. J., \& Rossell, S. L. (2015). Facial affect recognition in body dysmorphic disorder versus obsessive-compulsive disorder: An eye-tracking study. Journal of Anxiety Disorders, 35, 49-59. https://doi.org/10.1016/j.janxdis.2015.08.003

Veale, D., Kinderman, P., Riley, S., \& Lambrou, C. (2003). Self-discrepancy in body dysmorphic disorder. British Journal of Clinical Psychology, 42(2), 157-169. https://doi.org/10.1348/014466503321903571

World Health Organisation. (2018). ICD-11 International Classification of Diseases for Mortality and Morbidity Statistics. https://icd.who.int/browse11/l-m/enAgustina, I., \& Widhiastuti, H. (2021). Karakteristik Individu, Karakteristik Pekerjaan dan Kinerja Karyawan yang dimediasi oleh Motivasi Kerja pada Pembatik Putting Out System. $\begin{array}{llll}\text { PHILANTHROPY: Journal of Psychology, } & 5(1),\end{array}$ https://doi.org/10.26623/philanthropy.v5i1.3408

American Psychiatric Association, \& American Psychiatric Association (Eds.). (2013). Diagnostic and statistical manual of mental disorders: DSM-5 (5th ed). American Psychiatric Association.

Ardhani, A. N., \& Nawangsih, S. K. (2020). Pengaruh Acceptance and Commitment Therapy (ACT) terhadap Penurunan Kecemasan pada Perempuan Korban Kekerasan Seksual. $\begin{array}{llll}\text { PHILANTHROPY: Journal of Psychology, } & 4(1),\end{array}$ https://doi.org/10.26623/philanthropy.v4i1.2139

Ayu, W. T. (2020). Konsep Diri, Regulasi Emosi Dan Asertivitas Pada Mahasiswa. $\begin{array}{llll}\text { PHILANTHROPY: Journal of Psychology, } & 4(1), \quad 25\end{array}$ https://doi.org/10.26623/philanthropy.v4i1.1754

Deng, Y., Chen, Y., \& Liu, X. (2019). Romantic relationship and appearance-based rejection sensitivity: A moderated mediation model of self-rated attractiveness and appearance-contingent self-worth. Personality and Individual Differences, 142, 295300. https://doi.org/10.1016/j.paid.2018.09.010

Feijen, M. M. W., van Cruchten, C., \& van der Hulst, R. R. W. J. (2021). The Effect of Cranial Shape on Esthetic Self-Worth in Bald Men. Journal of Craniofacial Surgery, 32(1), 233-237. https://doi.org/10.1097/SCS.0000000000006916

Jamal, N. A., \& Sugiarti, R. (2021). Kontrol Diri Terhadap Agresivitas Pada Remaja Pemain Pro Game Online. PHILANTHROPY: Journal of Psychology, 5(1), 47. https://doi.org/10.26623/philanthropy.v5i1.3269 
Lai, C.-S., Lee, S.-S., Yeh, Y.-C., \& Chen, C.-S. (2010). Body Dysmorphic Disorder in Patients With Cosmetic Surgery. The Kaohsiung Journal of Medical Sciences, 26(9), 478-482. https://doi.org/10.1016/S1607-551X(10)70075-9

Malcolm, A., Labuschagne, I., Castle, D., Terrett, G., Rendell, P. G., \& Rossell, S. L. (2018). The relationship between body dysmorphic disorder and obsessive-compulsive disorder: A systematic review of direct comparative studies. Australian \& New Zealand Journal of Psychiatry, 52(11), 1030-1049. https://doi.org/10.1177/0004867418799925

Overstreet, N. M., \& Quinn, D. M. (2012). Contingencies of Self-Worth and Appearance Concerns: Do Domains of Self-Worth Matter? Psychology of Women Quarterly, 36(3), 314-325. https://doi.org/10.1177/0361684311435221

Ronasih, M. Y., \& Widhiastuti, H. (2021). Kualitas Pelayanan, Faktor Emosional dan Persepsi Harga terhadap Loyalitas Konsumen melalui Kepuasan Konsumen. $\begin{array}{llll}\text { PHILANTHROPY: Journal of } & 109 .\end{array}$ https://doi.org/10.26623/philanthropy.v5i1.3303 